Document downloaded from:

http://hdl.handle.net/10251/148854

This paper must be cited as:

Payri, R.; Salvador, FJ.; Bracho Leon, G.; Viera-Sotillo, AA. (2017). Differences between single and double-pass schlieren imaging on diesel vapor spray characteristics. Applied Thermal Engineering. 125:220-231. https://doi.org/10.1016/j.applthermaleng.2017.06.140

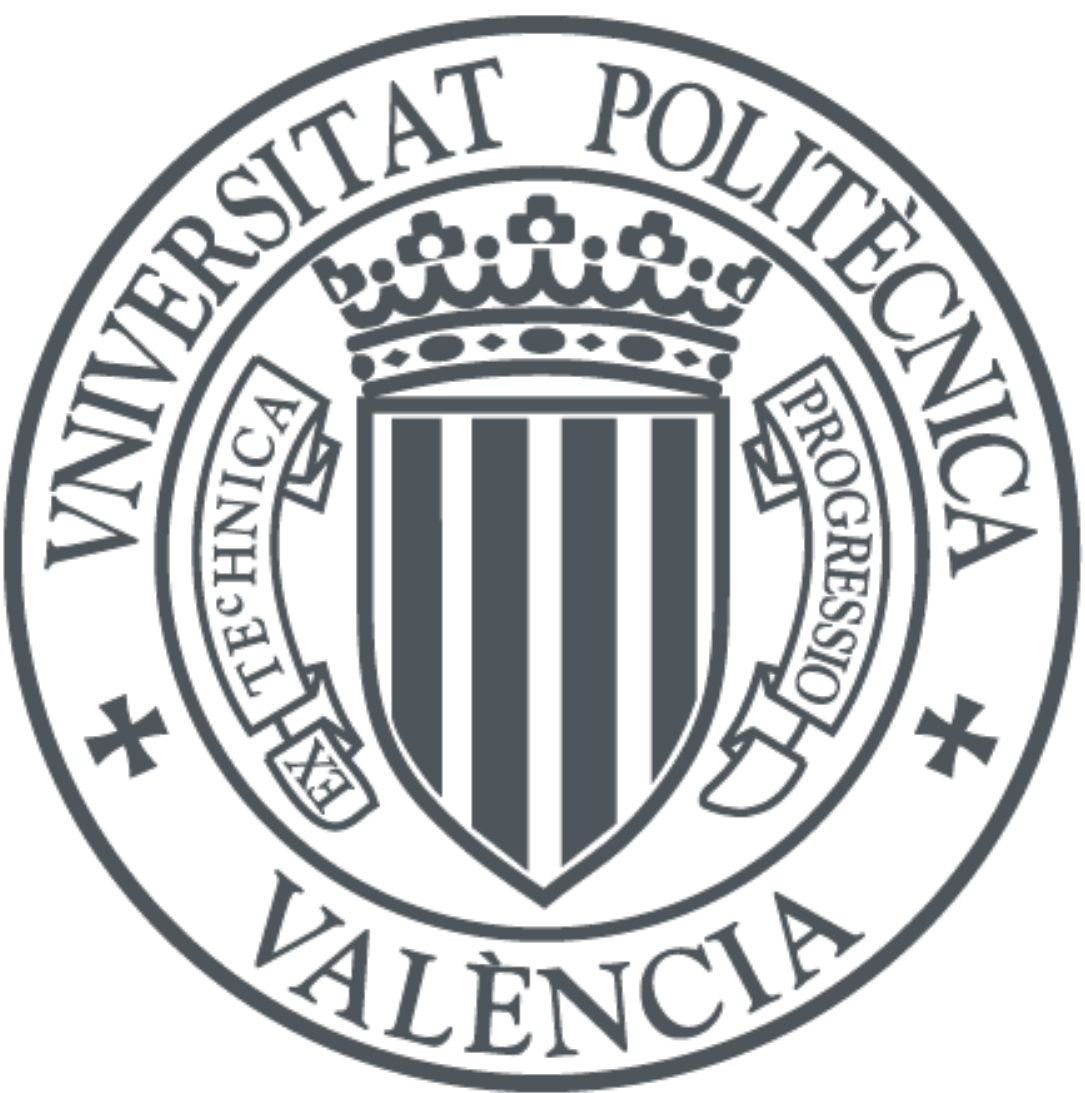

The final publication is available at

https://doi.org/10.1016/j.applthermaleng.2017.06.140

Copyright Elsevier

Additional Information 


\title{
Differences between single and double-pass schlieren imaging on diesel vapor spray characteristics
}

\author{
Raul Payri*, F. J. Salvador, Gabriela Bracho, Alberto Viera \\ CMT - Motores Térmicos, Universitat Politècnica de València, Edificio 6D, 46022, Valencia, Spain.
}

\begin{abstract}
The use of schlieren imaging at high acquisition rate has been adopted as a standard optical technique for the analysis of vaporizing diesel sprays under engine-like conditions. A singlepass schlieren arrangement is typically used for the study of axially drilled single-orifice nozzles, as vessels with multiple optical accesses regularly allow line of sight visualization. Contrarily, for multi-spray nozzles, measurements are commonly performed through a single optical access, in which case a double-pass arrangement is employed. As a consequence, the light beams pass through the test section twice, increasing the optical sensitivity of the schlieren setup. However, the influence this has on the macroscopic spray characteristics is still unclear. The scope of this study is to analyze the differences in vapor phase penetration and spreading angle measured for the same injection event, through high-speed imaging, for both single and double-pass schlieren configurations. Experiments were carried out with a three hole nozzle with a nominal orifice diameter of $90 \mu \mathrm{m}$, named Spray B from the Engine Combustion Network, using commercially available diesel fuel and in non-reactive conditions. The impact of different injection pressures, chamber temperatures and densities on the spray captured by each setup was assessed. On the results, vapor phase penetration and spreading angle followed the expected trend found in the literature, for the different boundary conditions tested. Comparing the optical setups, vapor phase penetration and spreading angle results obtained with the double-pass arrangement were marginally higher than those from the single-pass. The deviation was observed throughout all tested conditions. For spray tip penetration, although the discrepancy was approximately constant for different injection pressures and chamber temperature, it increased with increasing density. These results highlight the importance of a proper understanding regarding the limitations of optical diagnostics, in particular for results used in calibration of computational models.
\end{abstract}

Keywords: Diesel injection, schlieren, vapor phase penetration, spreading angle

\section{Introduction}

In recent years, the implementation of schlieren imaging in the experimental field has expanded to numerous applications that include military, industrial and scientific research.

\footnotetext{
${ }^{*}$ Corresponding author. E-mail address: rpayri@mot.upv.es
} 
Raul Payri, F.J. Salvador, Gabriela Bracho, Alberto Viera; Differences between single and double-pass schlieren imaging on diesel vapor spray characteristics. Applied Thermal Engineering, 2017, 125, 220-231.

As Settles [1] stated, it allows seeing optical inhomogeneities in transparent media, like air. 5 In small scale applications, these optical inhomogeneities can relate to density gradients in the medium through which light beams propagate. More specifically, in the field of diesel injection, a schlieren setup, coupled with high-speed cameras and a proper image processing methodology, has become an essential tool for the study of vaporizing diesel sprays.

For many years, researchers have used schlieren imaging to analyze the transient vapor phase of the diesel sprays in both non-reactive and reactive conditions. With this technique it is possible to measure simple macroscopic parameters, like spray tip penetration and spreading angle [2 4], to more complex variables, like ignition delay [5-10] or even lift-off length [11. It is not only fundamental knowledge to understand how boundary conditions affect these variables, but the experimental data is necessary to validate computational tools, 5 such as 1-D models or computational fluid dynamics (CFD).

The principle of the schlieren application in diesel sprays is simple: the density gradients between the injected fuel and the gas, along the optical path, result in different refractive indexes for the light rays passing through the test section. Subsequently, the boundary between these elements can be depicted, allowing to segment the diesel spray from the background [12. However, the boundary observed by the schlieren setup is defined by its sensitivity, as each region is determined by the amount of refraction the optical arrangement can capture.

The two most common schlieren configurations are single-pass (SP) [2, 8, 19] and doublepass (DP) [4, 20-22]. Typically, the first setup is used for axially drilled single-orifice nozzles, where optical vessels with multiple access allow line of sight visualization. Contrarily, the double-pass setup is commonly used for multi-hole nozzles, where the sprays tend to be visualized through a single optical access. Consequently, the light crosses the test section twice, and the optical sensitivity theoretically increases by a factor of two [1].

Pickett et al. [23] studied the effect of a single-pass system with different spatial sensitivities for spray detection, where two pixel-to-millimeter were compared, but the optical sensitivity was not accounted for. Pastor et al. [12 performed a qualitative comparison of multiple diameters of the diaphragm in the plane of Fourier for a SP setup, thus modifying the optical sensitivity of the singlepass schlieren setup used. However, the comparison presented was for different injection events, and quantitative results of the impact on the 35 macroscopic characteristics of the spray were not presented, as it was not within the scope of their study.

The objective of the present study is to compare two different schlieren imaging setups and their capabilities in the measurement of vapor phase penetration and spreading angle if a diesel spray. Experiments were carried out using a Spray B injector from the Engine Combustion Network (ECN) dataset 24, which is a multi-orifice nozzle in which the three holes are not equally spaced. In consequence, one spray is optically isolated from the others, often referred as the spray of interest. Therefore, it can be visualized both as a single and multi-orifice nozzle for the same injection event. Parametric variations of injection pressure, chamber temperature, and gas density were carried out.

This report is divided into five sections. Followed by this introduction, the experimental 
Raul Payri, F.J. Salvador, Gabriela Bracho, Alberto Viera; Differences between single and double-pass schlieren imaging on diesel vapor spray characteristics. Applied Thermal Engineering, 2017, 125, 220-231.

\begin{tabular}{|llll|}
\hline \multicolumn{2}{l}{ Nomenclature } & & \\
$\delta$ & Off axis angle & $\mathrm{ECN}$ & Engine Combustion Network \\
$\epsilon$ & Angular deflection & $\mathrm{ET}$ & Energizing time \\
$\psi$ & Inclination angle & $\mathrm{P}_{i n j}$ & Injection pressure \\
$\rho$ & Gas density in the chamber & $\mathrm{S}$ & Furthest pixel penetration \\
$k_{G D}$ & Gladstone-Dale constant & $\mathrm{S}_{x}$ & Furthest pixel axial penetration \\
$L$ & Optical path length & $\mathrm{S}_{D P}$ & Double-pass projected penetration \\
$n$ & Refractive index & $\mathrm{SOI}$ & Start of injection \\
$n_{0}$ & Refractive index of surroundings & $\mathrm{SP}$ & Single-pass \\
$\mathrm{DP}$ & Double-pass & $\mathrm{T}$ & Chamber temperature \\
& & & \\
\hline
\end{tabular}

facility is briefly mentioned, along with a detailed description of the schlieren principle, optical setups, and image processing methodology. Then, the results are presented, grouped by variations of injection pressure, chamber temperature, and density, with a short discussion of each case. Subsequently, the next part offers a deeper analysis of the results obtained with additional contour data for comparison. In the last section, the main conclusions are drawn.

\section{Materials and methods}

This section presents the experimental equipment, optical setup, and processing methodology used.

\subsection{Test vessel and fuel delivery system}

A high pressure and temperature vessel, with three optical accesses, was used. The facility is capable of providing nearly quiescent and steady thermodynamic conditions for experimental spray measurements, relevant to the diesel engine. The test chamber presents constant pressure and flow throughout its section, while a group of compressors, high-pressure reservoirs, and heaters provide the necessary conditions for testing purposes. The facility is explained in more detail in the work of other authors [4, 8, 25]. The fuel delivery system is made up of commercially available components. A Bosch CP3 pump, powered by an electric engine, supplies high-pressure fuel to a common rail with a pressure regulator driven by a PID controller.

The Spray B nozzle (reference 211200) is thoroughly described in the ECN website [24]. It consists of a three orifice nozzle, where only the spray of interest is studied, which is located at $180^{\circ}$ relative to the fuel inlet port. The nozzle outlet diameter is $93.2 \mu \mathrm{m}$, with a $k$-factor of 1.5 [26], and a nominal inclination angle of $17.5^{\circ}$. 
Raul Payri, F.J. Salvador, Gabriela Bracho, Alberto Viera; Differences between single and double-pass schlieren imaging on diesel vapor spray characteristics. Applied Thermal Engineering, 2017, 125, 220-231.

\subsection{Schlieren principle}

Light rays propagate uniformly through homogeneous media, but they are refracted proportional to the refractive index of the medium they are traveling [1]. Gladstone and Dale [27] found that there is a linear relationship between the refractive index and gas density, presented in Eqn. 1. Where $n$ is the refractive index, $\rho$ is the gas density, and $k_{G D}$ is the Gladstone-Dale coefficient.

$$
n-1=k_{G D} \rho
$$

Additionally, the angular deflection $\varepsilon$ of a ray in the perpendicular plane $x-y$, of a light beam that is traveling in a direction $z$ can be obtained by the expression [1]:

$$
\varepsilon_{x}=\frac{L}{n_{0}} \frac{\partial n}{\partial x} \quad, \quad \varepsilon_{y}=\frac{L}{n_{0}} \frac{\partial n}{\partial y}
$$

Where $L$ represents the optical path length, and $n_{0}$ the refractive index of the surroundings. From equations 1 and 2 , there is a clear relationship between the changes in density and angular deflection of light rays, that can be visualized through schlieren or shadowgraph imaging. Although both methods are closely related, the use of a cutoff for the refracted light in schlieren systems differentiates each configuration. As explained by Settles [1], a schlieren image responds to the first spatial derivative of the refractive index, whereas the shadowgram responds to the second spatial derivative. That is, the schlieren image captures the deflection angle of a ray (equation 2), while shadowgraphy shows the ray displacement as a result from the deflection [1]. Accordingly, for small disturbances (density gradients), schlieren imaging has the advantage of higher sensitivity.

In Figure 1, $a$, where a basic single-pass arrangement is presented, beams from a point light source are collimated by a lens. Any rays deflected $\alpha$ degrees by density gradients in the test section (trajectory $i$ in the figure) are blocked by a slit located at the focal distance of the second lens (or cut-off plane). On the contrary, non-deflected beams ( $i i$ in the figure) can pass through the slit and reach the screen. In theory, this produces a black and white image, because the light source is infinitesimal and located exactly at the focal distance of the first lens. Thus each point in the test section is illuminated by a single light ray. But in real practice, sources of illumination are finite. Thus the diagram of the setup is more similar to the one presented in Figure 1. $b$. Here, the schlieren object in the test section is illuminated by multiple infinitesimal $\partial j$ light sources. In consequence, the image assembled by the second lens is a composition of sub-images, formed by each bundle of rays from each $\partial j$ source [1]. More importantly, this gives the schlieren setup a continuous dynamic range, in the form of gray-scale intensities (combination of trajectories $i$ and $i i i$ ), compared to the black and white resolution from the first example.

An schematic diagram of a double-pass setup is presented in Figure 1. $c$, where a mirror replaces the second lens of the single-pass system. As light rays travel twice through the schlieren object (test section), they are diverted once again by the density gradients, boosting the maximum deflection a ray can achieve [1. Additionally, the optical sensitivity can be controlled by the size of the slit. Reducing the aperture is directly related to a decline in minimum deflection angle not blocked by the cutoff [12]. 


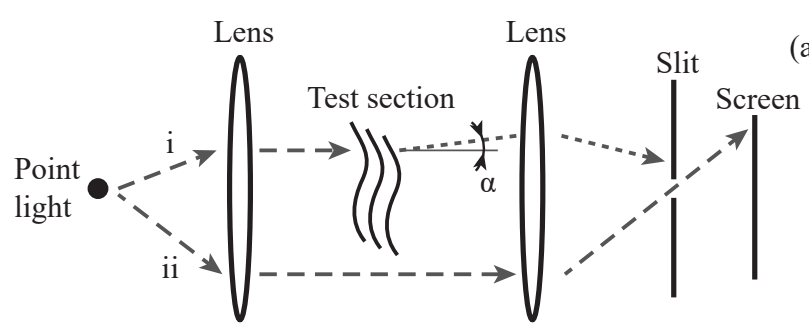

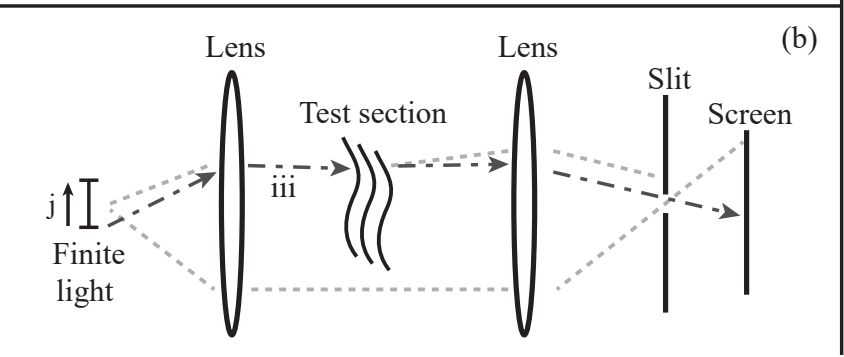

(c)

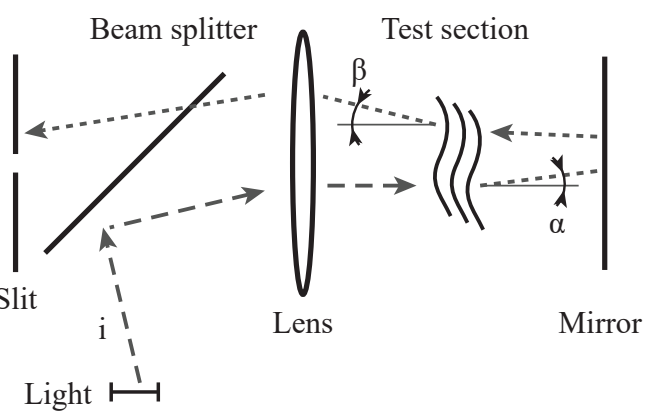

i. Deflected ray blocked by slit ii. Non-deflected ray

iii. Deflected ray not blocked by slit $\alpha$. Deflection angle of a single-pass $\beta$. Deflection angle of a double-pass

Figure 1: Differences between a point (a) and finite (b) light sources for a single-pass setup. (c) presents the light trajectory of a ray that passes twice through the test section in a double-pass configuration.

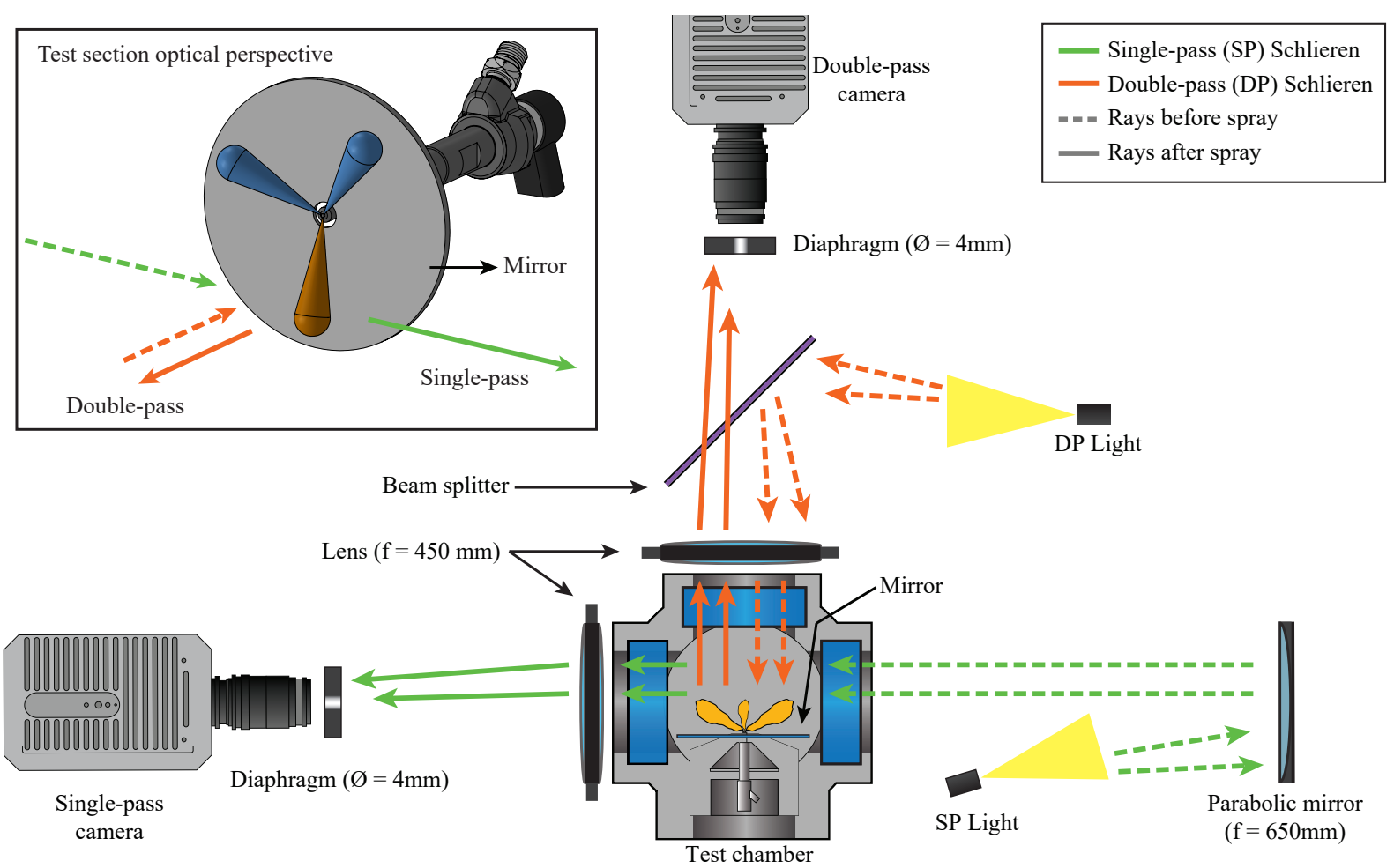

Figure 2: Optical setup used for vapor phase visualization with both single and double-pass schlieren arrangements for the same injection event. Diagram is not to scale. The top right corner presents the optical perspective of the test section, with the spray of interest highlighted in orange. For a better color interpretation of this figure, the reader is referred to the web version of this article. 
Raul Payri, F.J. Salvador, Gabriela Bracho, Alberto Viera; Differences between single and double-pass schlieren imaging on diesel vapor spray characteristics. Applied Thermal Engineering, 2017, 125, 220-231.

\subsection{Optical setup for vapor phase visualization}

Following the principles explained in the previous section, both single and double-pass schlieren setups were used to study the vapor phase of a diesel spray for the same injection event, and are presented in Figure 2.

For the single-pass configuration (light trajectory in green), the illumination source was located at the focal distance of a parabolic mirror instead of a regular lens, in contrast to the previous diagram. The angle between the light source and the optical axis of the SP setup was minimized as a result of two factors. Firstly, the long focal distance of the mirror. Secondly, because only one plume is visualized, the source was positioned just above the optical axis, with the minimum angle that allowed the visualization of the spray of interest. As a result, coma aberration was minimized, and the uniformity of the background illumination was improved [1].

In the double-pass configuration (light trajectory in orange), because the spray is visualized through one optical access, a high-temperature mirror is used. Therefore, a beam splitter (50:50) is needed to maintain the optical axis aligned with the other components of the DP setup, similar to the diagram presented in Figure 1.c. As a consequence, only $25 \%$ of the original light reached the cut-off plane. However, as the power output of the illumination source was not a constraint, both setups were calibrated with the same background intensity and uniformity before measurement.

Additionally, the top left corner of Figure 2 presents the optical perspective inside the test chamber, where the spray of interest is colored in orange. Note that, due to the fact that the high-temperature mirror did not fully enclose the nozzle of the injector, the minimum penetration measurable by the DP setup was $6 \mathrm{~mm}$. Dashed and continuous lines represent the rays before and after passing through the spray, respectively.

The diameter for both diaphragms was set to $4 \mathrm{~mm}$, to have the same sensitivity at the cut-off plane. Previous authors [4, 8, 12] proved that this diaphragm size provides a proper balance for spray and background segmentation for the schlieren setups in the facility. Both cameras were set to the same speed, resolution, exposure, and equipped with the same lens. Table 1 presents a summary of the optical configuration.

Table 1: Optical configuration.

\begin{tabular}{lcc}
\hline & Single-pass & Double-pass \\
\hline Path length & $200 \mathrm{~mm}$ & $250 \mathrm{~mm}$ \\
Camera & Photron SA5 \\
Camera lens & Zeiss $100 \mathrm{~mm}$ \\
Frame rate & $50 \mathrm{kfps}$ \\
Exposure & $10 \mathrm{\mu s}$ \\
Light source & Continous xeon-arc \\
Pixel-mm & $11.4 \mathrm{px} / \mathrm{mm}$ \\
Cut-off & $4 \mathrm{~mm}$ \\
\hline
\end{tabular}


Raul Payri, F.J. Salvador, Gabriela Bracho, Alberto Viera; Differences between single and double-pass schlieren imaging on diesel vapor spray characteristics. Applied Thermal Engineering, 2017, 125, 220-231.

\subsection{Image processing methodology}

In general terms, image processing methodologies are based on strategies to segment the spray and background. Anything that deflects the rays that travel across the test section could be visualized by the schlieren setup, depending on the sensitivity and the degree of deflection. For example, boundary layers of flowing hot gases, or subtle uneven temperature distributions in the chamber. In consequence, the images gathered with a schlieren setup have a very distinctive background structure.

The procedure used to depict the spray contour is a composition of two extensively used approaches. The core of the segmentation algorithm is based in a fixed threshold intensitysensitive method [3, 4, 8, 14, 20]. But to improve the contour detection capabilities, an image-temporal-derivative approach [12, 28, 29] was added. Each method produces grayscale images, which are then combined with an adjustable weighted average. This way, the two approaches complement each other.

The fixed threshold method is based on binarizing the image with an intensity level, usually calculated as a constant percentage (or fixed threshold) of the dynamic range of a frame. This procedure is not only used for processing schlieren images, but also for other optical techniques like Mie scattering [4, or diffused back illumination [30]. It is important to provide the methodology a frame with most of the background removed. Therefore, the most difficult task is to achieve a proper background subtraction, especially in schlieren, as it presents pixel structures of the same intensity level as the spray. Following the procedure used by Payri et al. [4, 7] a dynamic-background-composition strategy is employed, with the addition of black pixels correction, the steps are also described in Figure 3. $a-f$ :

- For a time step $i$, the background for subtraction $I_{b g}$, for the image $I_{i}$, is a composition of two areas, that is, $I_{b g}=I_{a}+I_{b}$.

- $I_{a}$ is built with the pixels from the previous image $I_{i-1}$ that were not detected as the spray (Figure 3.c).

- $I_{b}$ is comprised of the remnant pixels which were identified as the spray in the previous image, which are filled with the original background before injection (Figure 3. $d$ ).

- Any pixels in $I_{b}$ that are below a set level, are forced to that intensity (for example 0.3 in a normalized scale). As spray pixels are also dark, it prevents information to be deleted from $I_{i}$ in the subtraction strategy.

Finally, the background-corrected image is inverted (Figure 3. $f$ ). This procedure provides the binarization algorithm a frame where the background have mostly been filtered. But still, one disadvantage of the intensity-sensitive method is detecting the contour of diluted regions of the spray. As fuel mixes in the chamber, the local density gradients of these areas resembles its surroundings. Therefore, the deflection angle of the rays is reduced, and in consequence, the contrast between the spray and background decreases. Although lowering the threshold level, in these cases, would help in the segmentation of the spray, it also implicates the detection of non-spray pixels. 
Raul Payri, F.J. Salvador, Gabriela Bracho, Alberto Viera; Differences between single and double-pass schlieren imaging on diesel vapor spray characteristics. Applied Thermal Engineering, 2017, 125, 220-231.

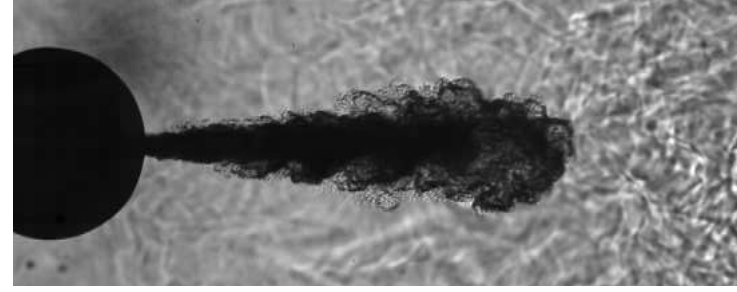

(a) Image for processing in a time step $i$.

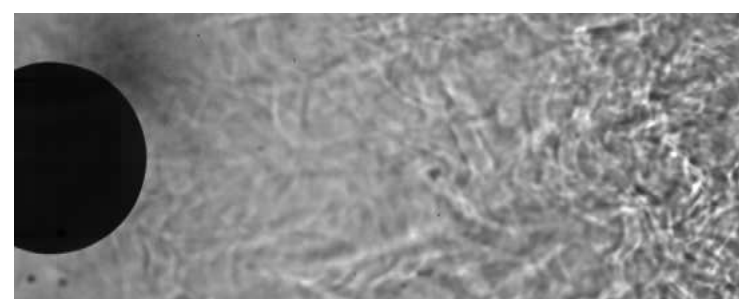

(b) Averaged background before injection.

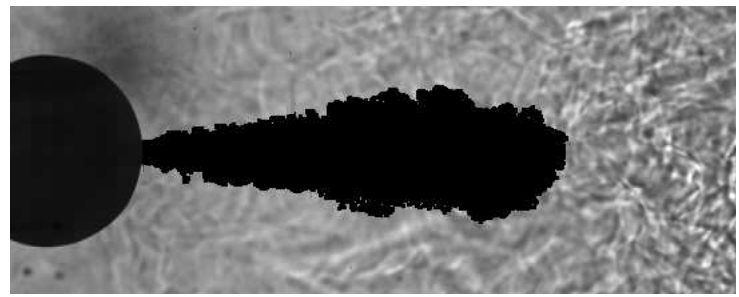

(c) Background from the non-spray pixels of the previous image.

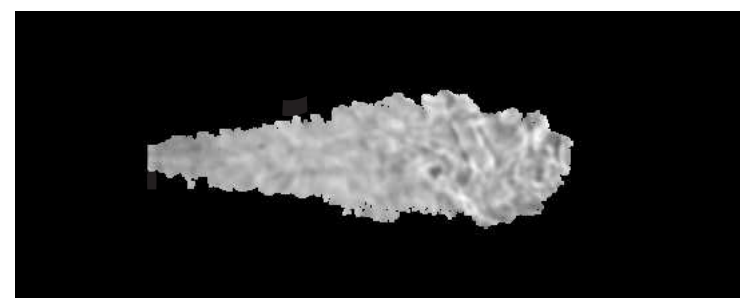

(d) Remnant pixels are filled with background from image (b).

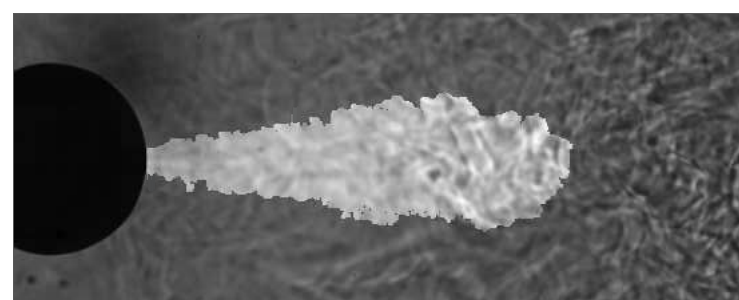

(e) Composed background, boundaries highlighted.

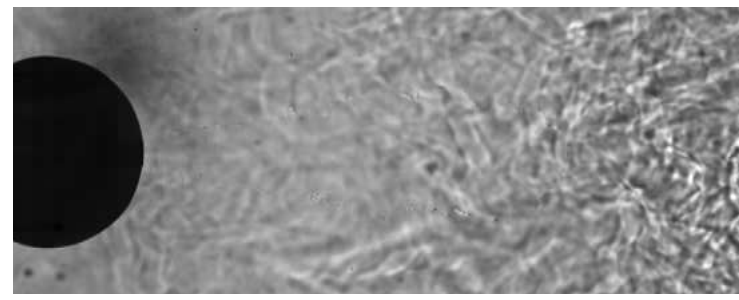

(f) Composed background for substraction.

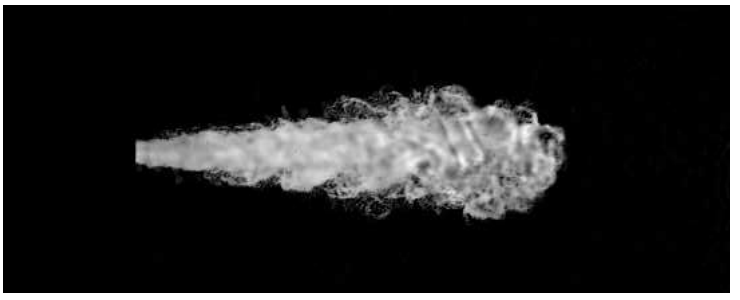

(f) Fixed threshold inverted image after background correction.

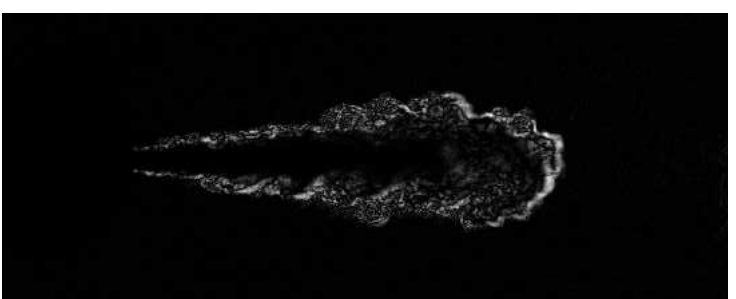

(g) Image from the temporal derivative approach.

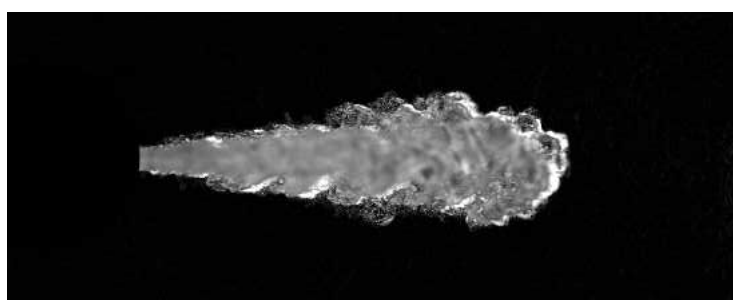

(h) Combined images (f, g) for the contour detection algorithm.

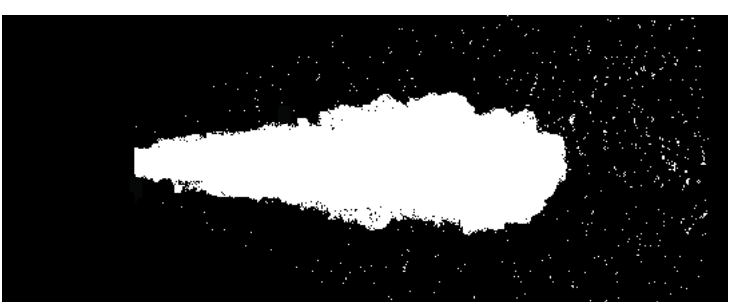

(i) Raw binarized image with fixed thresholding.

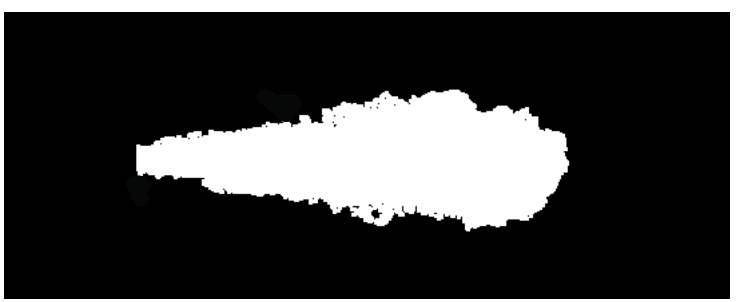

(j) Binarized image after cleaning algorithms.

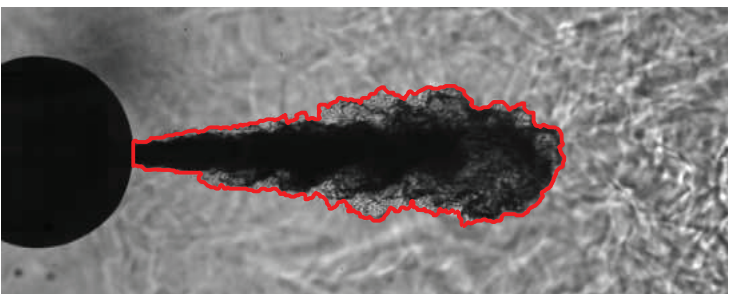

(k) Contour detection result for time step $i$.

Figure 3: Example of the processes invoßved in the contour detection algorithms. 
Raul Payri, F.J. Salvador, Gabriela Bracho, Alberto Viera; Differences between single and double-pass schlieren imaging on diesel vapor spray characteristics. Applied Thermal Engineering, 2017, 125, 220-231.

The image-temporal-derivative approach works very well for capturing the contour of a spray in diluted regions. It detects temporal changes in intensity by calculating the pixelwise standard deviation of a series of images. But, when the intensity levels of the pixels do not change (i.e. the liquid portion), the approach is not able to detect the spray correctly. In this work, the deviation was calculated for three consecutive images, that is, for a time step $i$, the pixel-wise standard deviation was determined between $i, i-1$ and $i-2$. An example is presented in Figure $3 . \mathrm{g}$.

The combination of both approaches provides the fixed threshold criteria with a sharp image (Figure 3.h). Image binarization (Figure 3. $i$ ) is performed as proposed by Siebers [31], with a set level of the dynamic range, set at 3.5\% for all test conditions. Noise is ruled out with erode-dilate strategies and pixel connectivity evaluation [20] (Figure 3.j). From the resultant image, the coordinates of the black and white boundaries are obtained and can be depicted (Figure 3. $k$ ).

\subsection{Definition of the macroscopic spray variables}

With the contour of the spray defined, the next step is to calculate the macroscopic 190 variables for comparison. Regularly, the spray tip penetration is defined as the furthest pixel from the orifice exit, measured in polar coordinates. But, as shown in Figure 2, the spray is observed through different perspectives. The single-pass setup visualizes the real development of the spray, because its axis is parallel to the plane of the camera sensor. Contrarily, the double-pass arrangement captures a projection of the spray evolution, so it is necessary to correct the tip penetration with the inclination angle. The definition of the spray tip penetration and spreading angle are presented in Figure 4 , the following considerations are done:

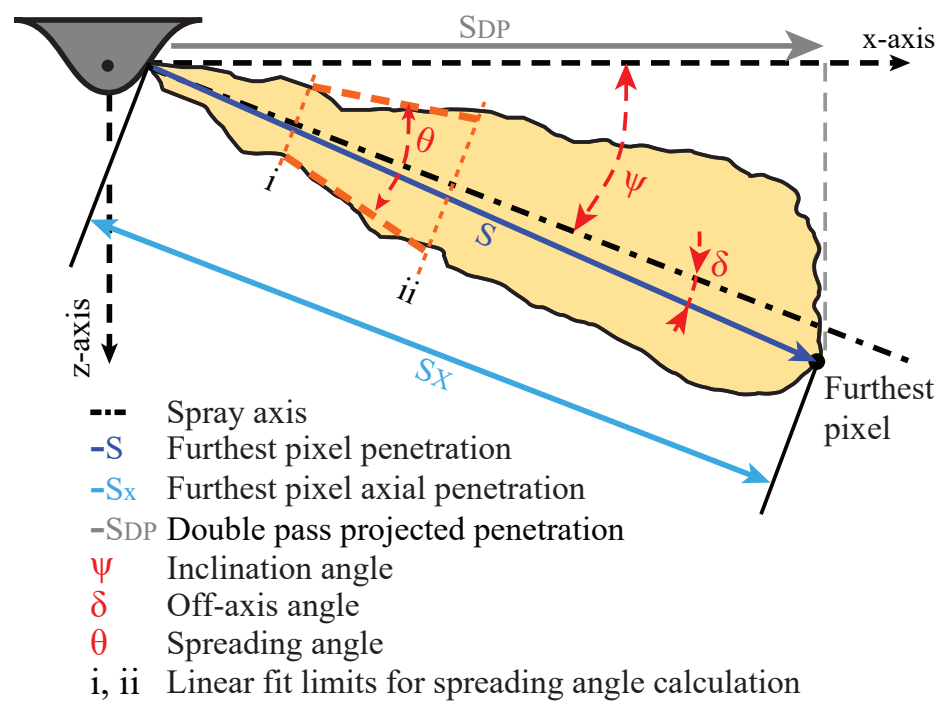

Figure 4: Definition of the macroscopic spray variables used for comparing single and double-pass schlieren setups. 
Raul Payri, F.J. Salvador, Gabriela Bracho, Alberto Viera; Differences between single and double-pass schlieren imaging on diesel vapor spray characteristics. Applied Thermal Engineering, 2017, 125, 220-231.

- The furthest pixel might not be located at the same position for each setup. In consequence, tip penetration (S) could be measured in different geometrical positions of the spray. But the low value of the nozzle inclination angle, and the plume-shaped spray, minimizes the chances of this happening, and its impact on the results.

- The spray tip penetration, measured through the double-pass setup $\left(S_{D P}\right)$, needs to be corrected with the inclination angle $\psi$. But, as mentioned by Payri et al. [30, this angle fluctuates during the injection event.

- The furthest pixel is not contained in the spray axis. Consequently, the correction has to account also the off-axis angle $\delta$.

Considering the previous points, the variable proposed for comparison is the furthest axial penetration (see Figure 4). Since it is parallel to the spray axis, it is always corrected with a constant inclination angle of $16.75^{\circ}$, reducing the uncertainties due to the spray axis and off-axis angle corrections for the DP spray tip penetration. The inclination angle was measured with the single-pass configuration.

The spreading angle is obtained with a definition similar as the one used by previous authors [3, 30, 32, and presented in Figure 4. It is based on measuring the angle between two linear fits, where each is calculated for the top and bottom profile of the spray (divided through its axis), respectively. The linear fits are computed with all the contour data contained between $i=10$ and $i i=25 \mathrm{~mm}$ from the nozzle.

\subsection{Data averaging and start of injection}

With the procedures explained in the previous section, the raw results, gathered through high-speed imaging, produce a significant amount of data repetition-wise. Therefore, a moving average technique, described in detail by Payri et al. [33], is used to calculate a single time-dependent curve for each macroscopic variable studied.

For a time instant $t_{i}$, the correspondent value of the variable being averaged $f\left(t_{i}\right)$, is computed with the linear regression $f(t)=k t+b$. The fitting constants $k$ and $b$ are calculated by solving the regression with $t$ and $f(t)$ consisting of all the data contained in the time interval $t_{i} \pm \Delta t$, with $\Delta t=150 \mu \mathrm{s}$. Subsequently, the average value $\bar{f}$ is estimated by evaluating $t_{i}$ in the regression previously solved. This process is repeated for each time-step up to the end of injection.

Fuel is delivered to the chamber with a certain delay after the injection command signal is sent, known as the hydraulic delay. Although all test conditions are measured with the same zero reference in the time domain, which is the start-of-energizing (SOE) of the injector, the hydraulic delay depends on the boundary conditions [34]. Therefore, it is necessary to estimate the start-of-injection (SOI) in order to phase the time domain of the results and properly compare test points with different initial conditions.

The SOI is calculated by extrapolating the penetration curve to zero, that is $t(S=0)$, with a quadratic fit $[20,29,30,33$. As mentioned before, the high-temperature mirror in the double-pass setup makes it not possible to observe the first few millimeters of penetration. Consequently, extrapolations for the start-of-injection can produce improper estimations. 
Raul Payri, F.J. Salvador, Gabriela Bracho, Alberto Viera; Differences between single and double-pass schlieren imaging on diesel vapor spray characteristics. Applied Thermal Engineering, 2017, 125, 220-231.

But since the same injection event was recorded with both configurations, the SOI was calculated only with the SP data, and then copied to the double-pass data.

\subsection{Test conditions}

Experimental conditions are listed in Table 2. Values include a parametric sweep in injection pressure, chamber temperature, and density, following ECN recommendations [24]. A $2.5 \mathrm{~ms}$ energizing time (ET) was used for stabilized angle measurement. Experiments were carried out in a non-reactive environment with commercially available diesel fuel, which properties can be found in previous work [35].

Table 2: Test conditions.

\begin{tabular}{lll}
\hline Parameter & Value & Units \\
\hline Fuel & Diesel $^{*}$ & - \\
Fuel density & 825 & $\mathrm{~kg} / \mathrm{m}^{3}$ \\
Fuel viscosity & 2.34 & $\mathrm{~mm}^{2} \mathrm{~s}^{-1}$ \\
Energizing time & 2.5 & $\mathrm{~ms}$ \\
Injection pressure $\left(P_{\text {inj }}\right)$ & $50-100-150$ & $\mathrm{MPa}$ \\
Chamber temperature $(T)$ & $800-900$ & $\mathrm{~K}$ \\
Chamber density $(\rho)$ & $7.6-15.2-22.8$ & $\mathrm{~kg} / \mathrm{m}^{3}$ \\
Gas & Nitrogen & - \\
Repetitions & 10 & - \\
\hline * Properties measured at 313K [35]. & &
\end{tabular}

\section{Results and discussion}

This section presents the comparison between the single and double-pass schlieren configurations in multiple aspects, including the mentioned macroscopic spray variables.

\subsection{Background distribution and spray contrast}

As referred to in section 2.4, the background of images captured with a schlieren setup displays a unique structure, because it contains the density gradient information of all the optical path. Not only there is a difference in the distance and trajectory traveled by the light rays inside the test section, but as previously commented, the double-pass arrangement has, theoretically, twice the sensitivity [1]. Figure 5. $a-d$ presents the backgrounds before injection for different chamber temperature and densities. Each column represents images from the SP (left) and DP (right) setups. From this perspective, the hot gas from the heater enters the test section from the right side of the frames.

Focusing in Figure 5. a, the mirror mounted for the DP setup created a stream of flow cooler than the surroundings, marked with a dashed red arrow, and observed throughout 
Raul Payri, F.J. Salvador, Gabriela Bracho, Alberto Viera; Differences between single and double-pass schlieren imaging on diesel vapor spray characteristics. Applied Thermal Engineering, 2017, 125, 220-231.
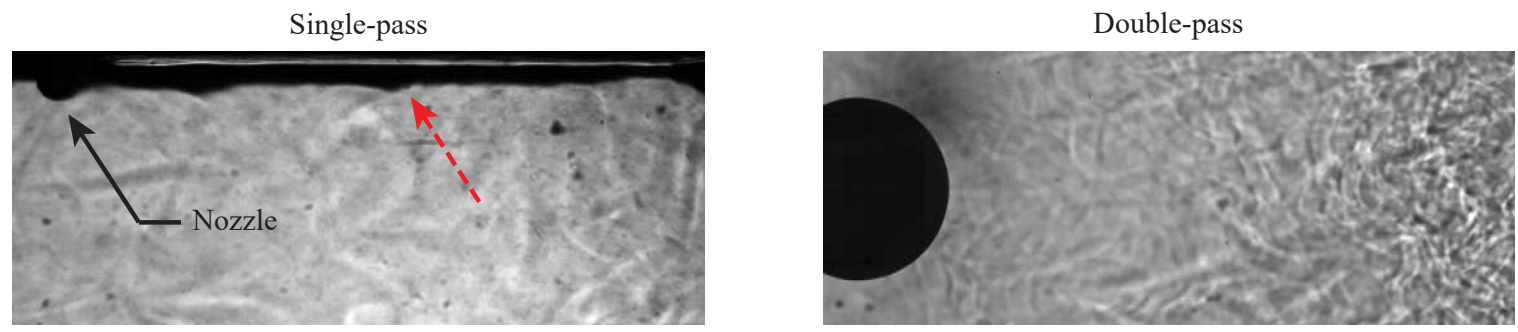

(a) Chamber temperature $=800 \mathrm{~K}$, density $=7.6 \mathrm{~kg} / \mathrm{m}^{3}$.
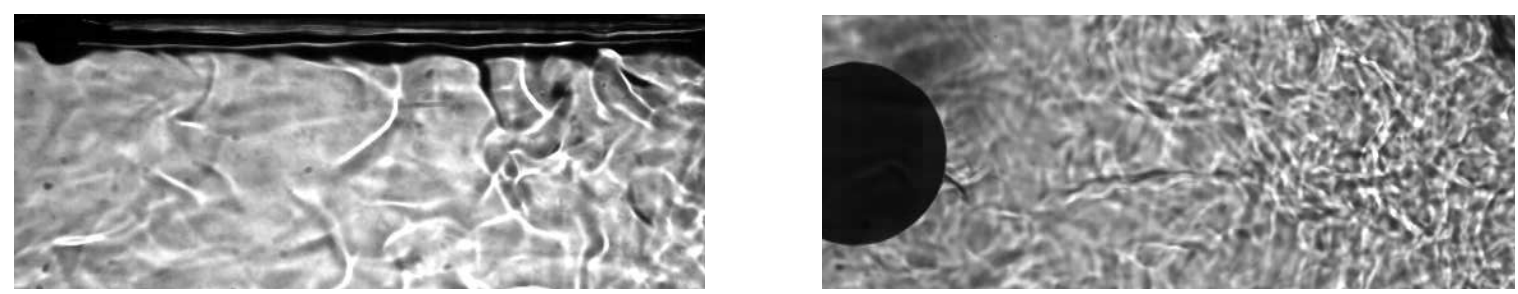

(b) Chamber temperature $=800 \mathrm{~K}$, density $=15.2 \mathrm{~kg} / \mathrm{m}^{3}$.
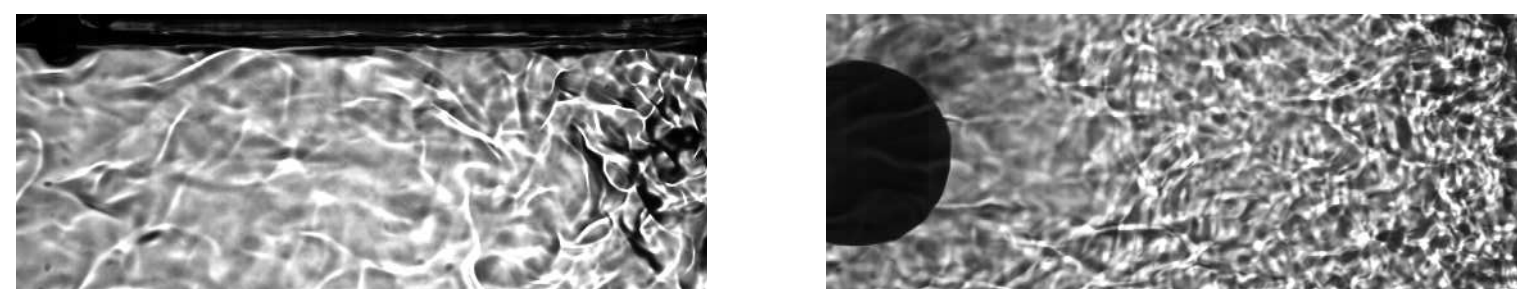

(c) Chamber temperature $=800 \mathrm{~K}$, density $=22.8 \mathrm{~kg} / \mathrm{m}^{3}$.
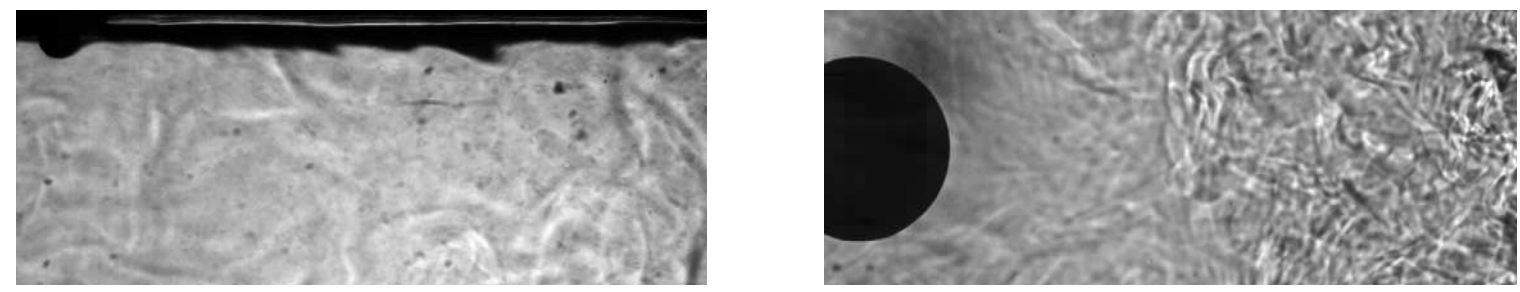

(d) Chamber temperature $=900 \mathrm{~K}$, density $=7.6 \mathrm{~kg} / \mathrm{m}^{3}$.
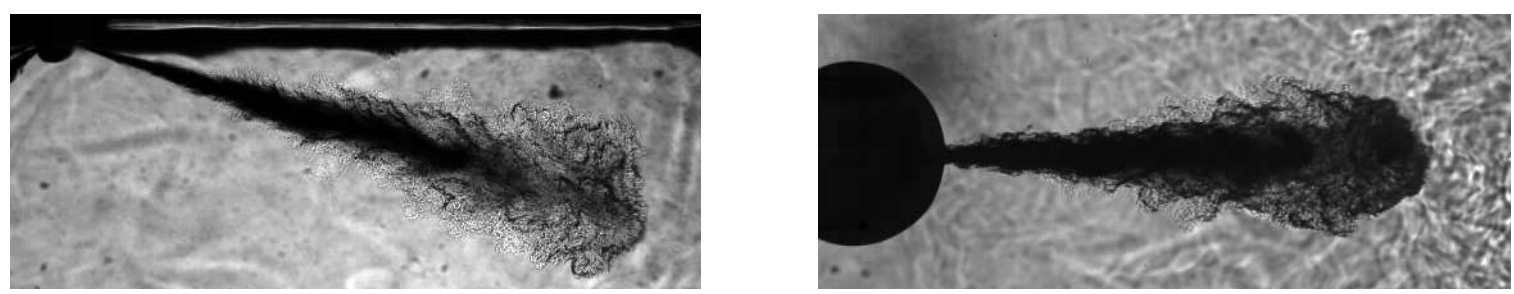

(e) Difference in spray contrast, chamber temperature $=800 \mathrm{~K}$, density $=7.6 \mathrm{~kg} / \mathrm{m}^{3}$.

Figure 5: Differences in background structures and spray contrast for the single (left) and double-pass (right) schlieren.

the experiments in the SP arrangement. In contrast, this was not visible in the doublepass images, because of the difference in the optical path length of this region for the each perspective. 
The influence of chamber density in the background for each optical setup is presented in Figure 5. $a-c$. For both systems, increasing the density increases the disturbances captured by the schlieren, as observed by Pickett et al. [23]. On the contrary, comparing Figures 5. $a$ and 5. $d$, suggests that chamber temperature produces fewer disturbances in the background, at least for the conditions tested. The marked impact of chamber density in the background is because of its linear scaling with gradients of refractive index [1, 23]. On the other side, the effect of temperature depends on its distribution along the test section. Additionally, the double-pass setup presents more complex background structures, with more details in local regions of the frame than the SP configuration. More interestingly, in Figure $5 . d$, the DP system captures with more detail the hot gases entering the test section.

The difference between optical setups on background structures, observed in Figures $5 . a-d$, are a consequence of at least two factors. On one side, the flow distribution of the hot gases is not strictly equal in each optical plane. On the other, and more importantly, the increased sensitivity for the DP system. Moreover, the optical path length $L$ of the schlieren object, in this case the test section, is also bigger for the double-pass setup. That is $\approx 250 \mathrm{~mm}$ compared to $\approx 200 \mathrm{~mm}$ for the SP, which is the distance traveled by the light rays inside the test section for each configuration.

The last comparison, Figure 5.e, presents a random time step in the latter part of the injection event for fixed boundary conditions. The clear difference of contrast between spray and background grants more evidence of the higher sensitivity of the double-pass configuration. In consequence, the DP setup provides images with sharper contours and a darker core to the image processing methodology.

\subsection{Spray tip penetration}

Following the definition from Figure 4, spray tip penetration results, for both schlieren setups, at different injection pressures are presented in Figure 6, for fixed conditions of chamber temperature and density. The dashed and continuous line represent both single and double-pass arrangements, respectively. The same line style format is maintained throughout the section. From that figure, both schlieren setups captured the effect of injection pressure in the tip penetration [2, 29, 30] equally, as it increases in about the same ratio with increasing rail pressure. More interestingly, the DP configuration depicts higher spray penetration values, being more notably in the later part of the injection event. No effect of the rail pressure in the difference is observed.

Figure 7 presents the spray tip penetration for different chamber temperature and fixed conditions of injection pressure and density. Once again, both optical setups captured almost identically the negligible effect of temperature in the spray evolution [20, 29]. Additionally, and in agreement with the results from Figure 6, the double-pass configuration also reports roughly higher penetration values, particularly downstream of the spray.

The last comparison, shown in Figure 8, depicts the effect of chamber density on the spray tip penetration. As observed in the two previous cases, both schlieren arrangements capture the effect of density in the spray development in agreement with the literature [20, 29]. However, even though the double-pass setup still depicts higher penetration values, 
Raul Payri, F.J. Salvador, Gabriela Bracho, Alberto Viera; Differences between single and double-pass schlieren imaging on diesel vapor spray characteristics. Applied Thermal Engineering, 2017, 125, 220-231.

the difference between the optical arrangements is reduced when decreasing the density, and reports almost identical values at the lowest level in the conditions tested.

The effect of the density on the difference between optical setups can by understood by analyzing the sensitivity of each configuration. The deflection caused by the diluted

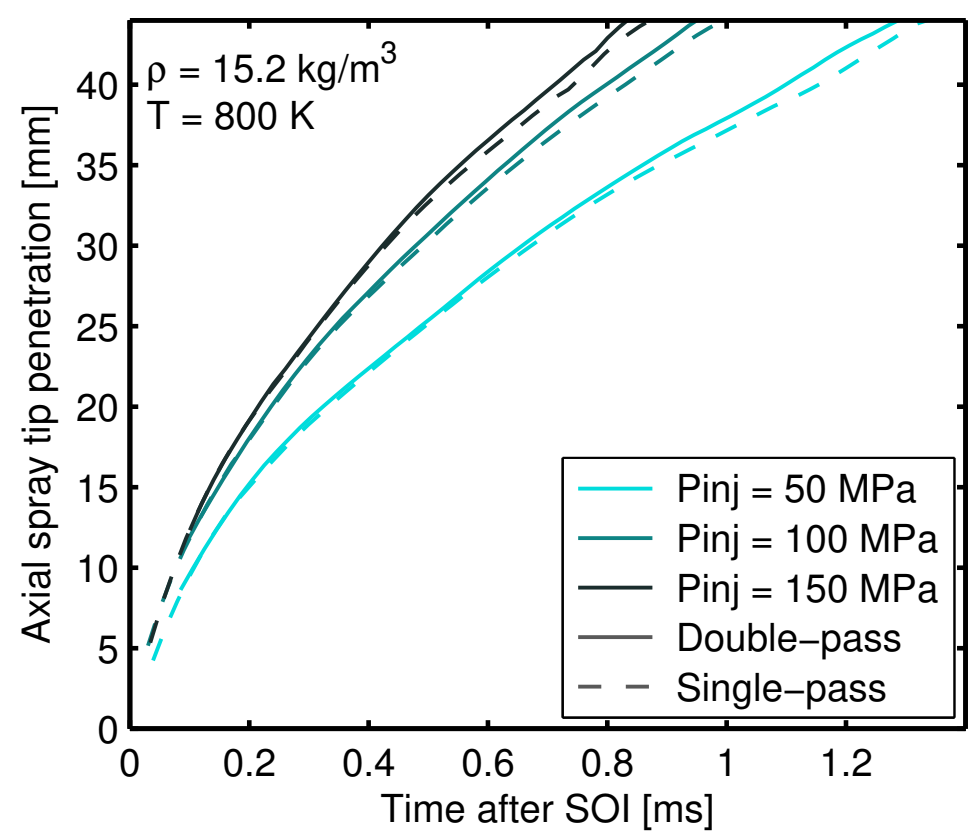

Figure 6: Spray tip penetration for both schlieren setups at different injection pressures.

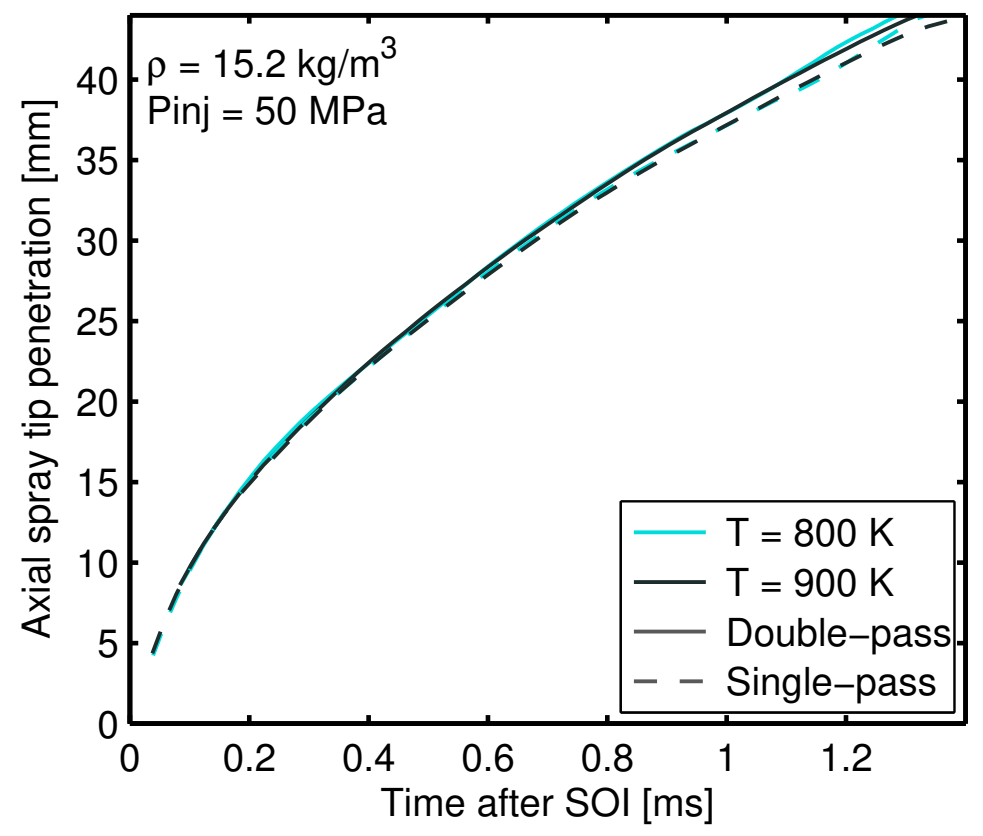

Figure 7: Spray tip penetration for both schlieren setups at different chamber temperatures. 
Raul Payri, F.J. Salvador, Gabriela Bracho, Alberto Viera; Differences between single and double-pass schlieren imaging on diesel vapor spray characteristics. Applied Thermal Engineering, 2017, 125, 220-231.

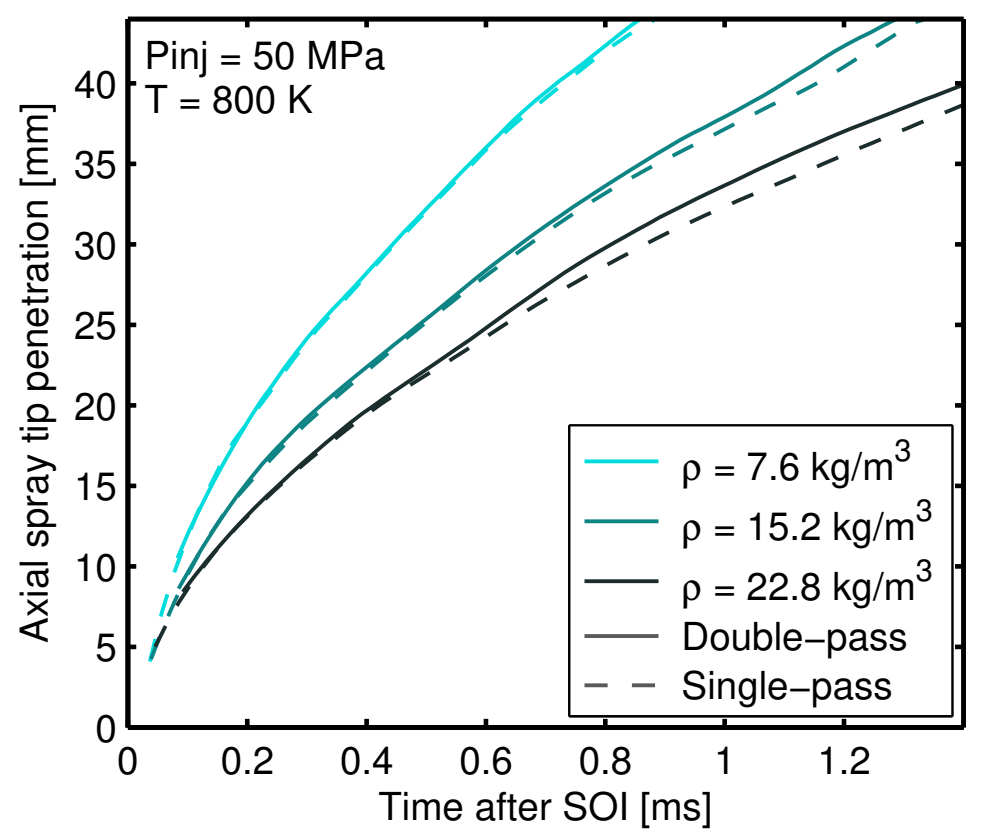

Figure 8: Spray tip penetration for both schlieren setups at different chamber densities.

regions of the fuel injected in the test section, given in Eqn. 2, depends on the refractive index of the surroundings, thus its density (Eqn. 1). Therefore, with the test section at $22.8 \mathrm{~kg} / \mathrm{m}^{3}$, the resultant deflection of a light ray passing through the spray is less than at $7.6 \mathrm{~kg} / \mathrm{m}^{3}$. Furthermore, the density gradients between these diluted regions of the sprays (contours or tip region at a latter part of the injection event) and the surroundings are lower, also producing smaller deflection angle in these areas. Consequently, due to the increased sensitivity of the DP configuration [1], the setup captures "more" spray in the same time step than the SP setup, even though they are visualizing the same injection event. Yet still, although the difference observed between the schlieren systems generally decreased for all density sweeps performed, other parameters, such as the optical perspectives, influence the results.

\subsection{Shot-to-shot deviation}

In the previous section, spray tip penetrations results were presented without the corresponding error. Following the methodology detailed in section 2, the error calculated through the moving average technique is the standard deviation of the raw data. Thus, it represents the shot-to-shot dispersion. An example of the spray tip penetration with the dispersion obtained is presented in Figure 9, for fixed conditions of chamber density, injection pressure and chamber temperature.

As observed in Figure 9, both optical systems present similar values of dispersion. Both curves are within the limits of the shot-to-shot deviation. Nevertheless, studying the evolution of spray tip penetration for single injection events further isolates the effect of the difference in sensitivity on the segmentation of the spray contour. Figure 10 presents five different injection events for the same fixed conditions as before. Repetitions from 2-5 were 
Raul Payri, F.J. Salvador, Gabriela Bracho, Alberto Viera; Differences between single and double-pass schlieren imaging on diesel vapor spray characteristics. Applied Thermal Engineering, 2017, 125, 220-231.

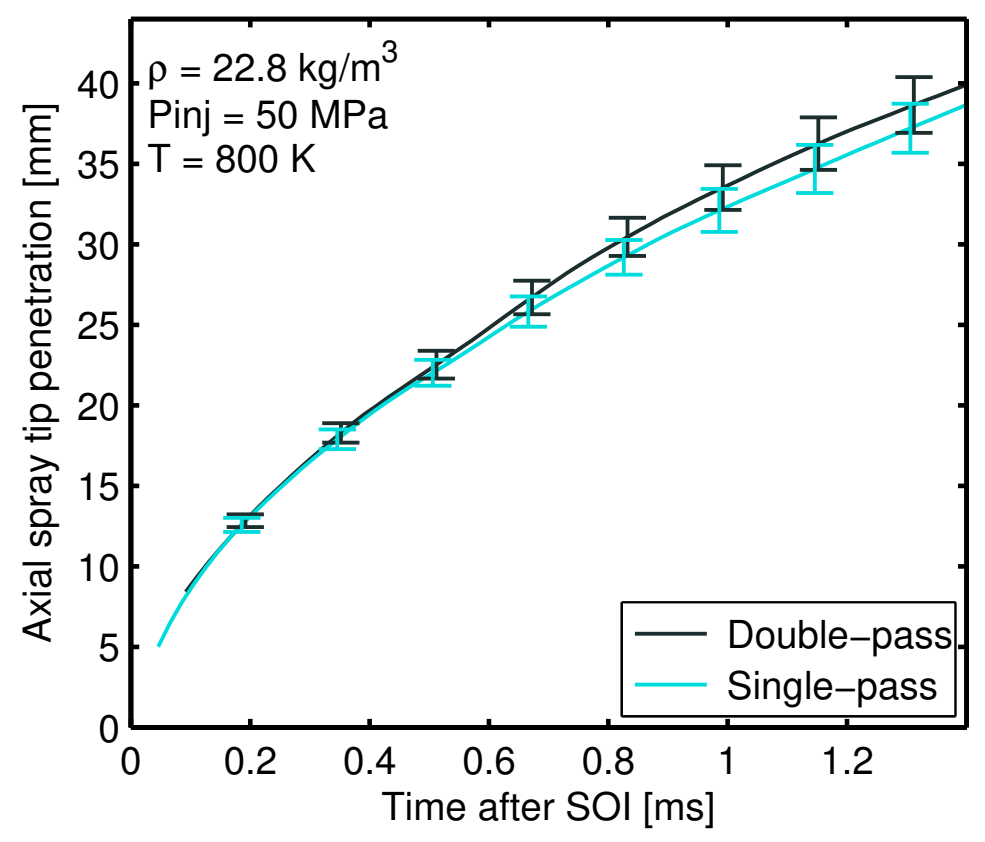

Figure 9: Spray tip penetration with shot-to-shot dispersion for both optical configurations.

delayed $0.3 \mathrm{~ms}$ accordingly, for the purpose of representation. From the figure, throughout all separate injection events, there is consistent to what was presented in the previous subsection, that is, the double-pass configuration depicts higher spray tip penetration at a later stage of the injection event when compared to the single-pass. Consequently, the moving average represents the mean value of separate injection events, thus shot-to-shot dispersion does not influence the trend observed.

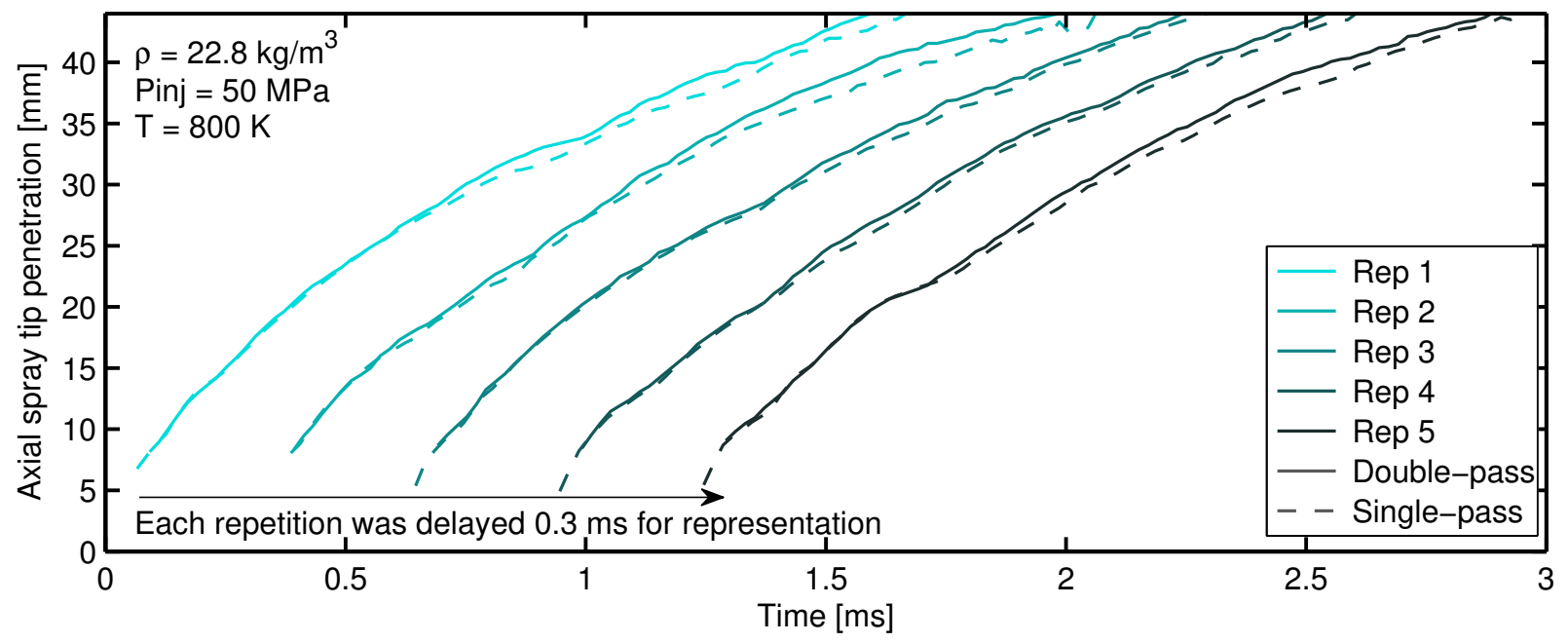

Figure 10: Differences between SP and DP arrangements for single injection events. 
Raul Payri, F.J. Salvador, Gabriela Bracho, Alberto Viera; Differences between single and double-pass schlieren imaging on diesel vapor spray characteristics. Applied Thermal Engineering, 2017, 125, 220-231.

\subsection{Effect of boundary detection}

As explained in section 2.4, the data gathered through experimental measurements are processed with the following steps: background correction, image binarization with thresholding, contour analysis to determine the macroscopic variables, moving average, and start of injection calculation. As both schlieren systems used, have theoretically different optical sensitivity [1, it is important to understand the impact of the threshold level, used for image binarization, in the results. Figure 11, presents the spray tip penetration calculated for different threshold levels, for fixed conditions of chamber density, injection pressure, and chamber temperature. From the figure, no effect of the thresholding percentage in the spray tip penetration is observed, as lines that represent different levels of each optical configuration overlap each other. The fact that the results do not depend on the threshold results in two considerations. Firstly, the background subtraction strategy presented in section 2.4 provides the binarization algorithm a clean and segmented frame. Secondly, the differences observed between both schlieren configurations are more related to the sensitivity of the optical systems than of the image processing methodology.

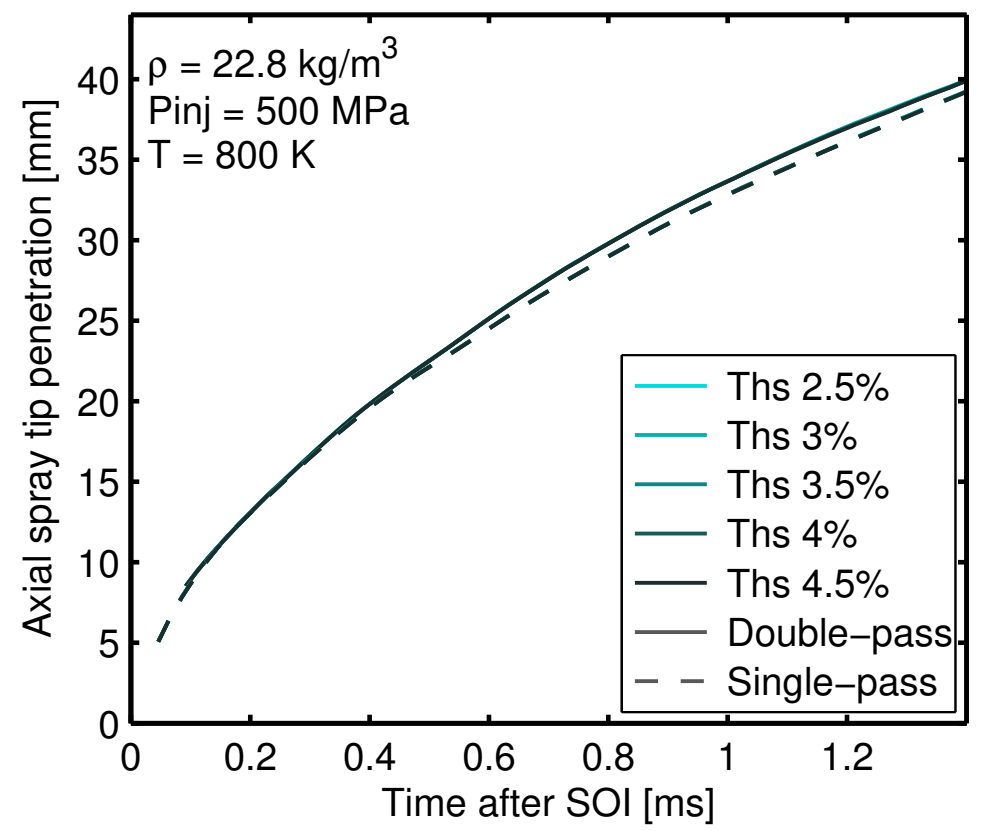

Figure 11: Effect of the thresholding level in the spray tip penetration. Lines for each threshold overlap each other. Reference level used for all test conditions is $3.5 \%$.

\subsection{Average spreading angle}

Many authors have pointed out that the calculation of spreading angle, in vapor phase penetration, is significantly affected by the optical sensitivity and the image processing routines [23, 28]. Additionally, the flow conditions at the exit of the nozzle are not equal in the planes of the spray being visualized, due to the inclination angle [36]. Consequently, and accounting for the two previous statements, the spray development regarding spreading angle 
Raul Payri, F.J. Salvador, Gabriela Bracho, Alberto Viera; Differences between single and double-pass schlieren imaging on diesel vapor spray characteristics. Applied Thermal Engineering, 2017, 125, 220-231.

can be different. But still, comparing the values obtained with each schlieren configuration gives an insight of the capabilities of each optical arrangement in the estimation of the macroscopic characteristics of the diesel spray.

Following the procedure employed by Payri et al. [30], to have a single value per test condition, an average value of the time-dependent spreading angle was calculated. The time window for the median was selected according to the stabilized rate of injection interval. The results obtained, for sweeps of the different boundary conditions studied, are shown in

Figure 12 .
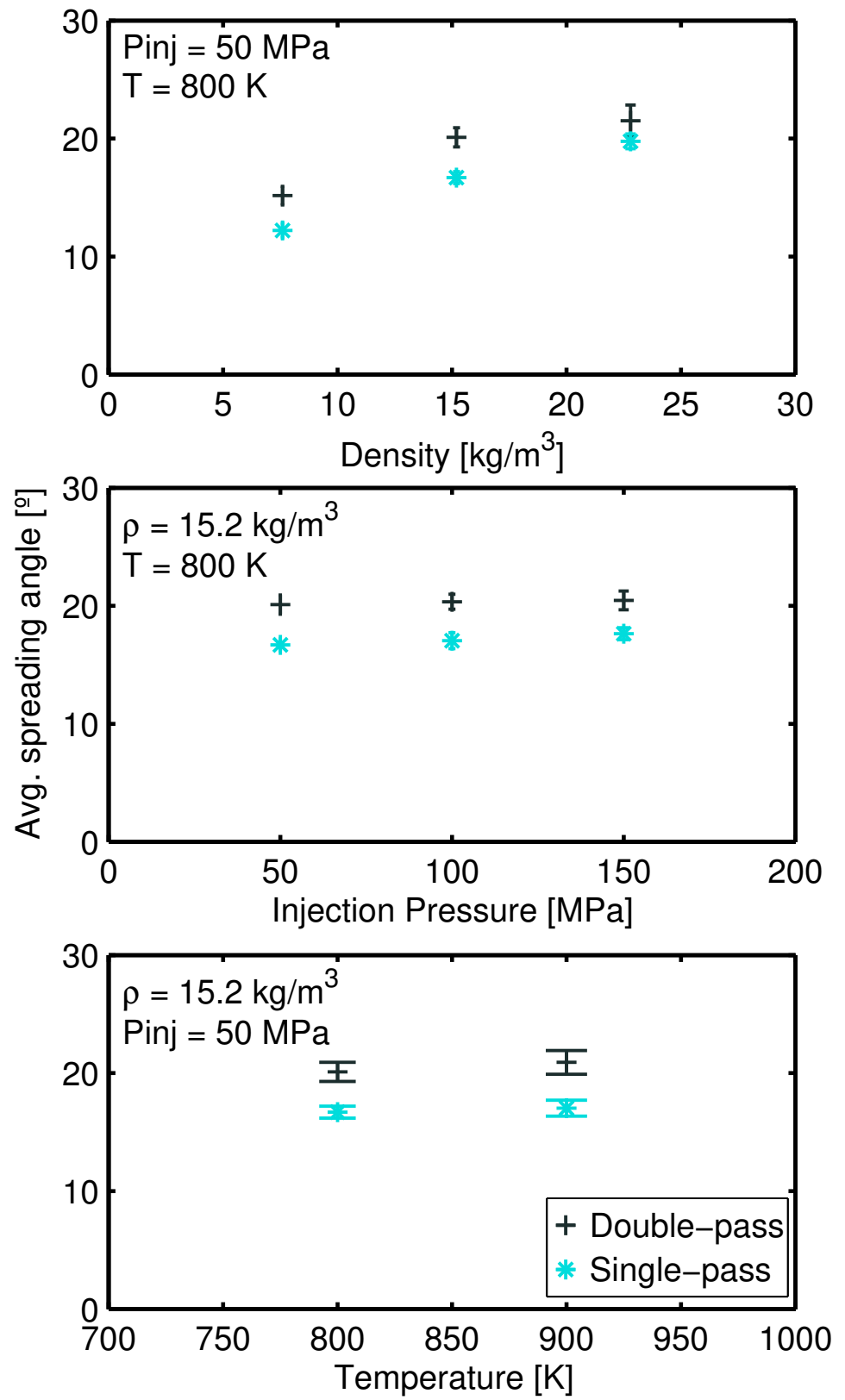

Figure 12: Average spreading angle for both optical configurations. 
Raul Payri, F.J. Salvador, Gabriela Bracho, Alberto Viera; Differences between single and double-pass schlieren imaging on diesel vapor spray characteristics. Applied Thermal Engineering, 2017, 125, 220-231.

From the figure, the spreading angle follows the expected trends observed by other authors [29, 30, 37, 38], it increases with increasing chamber density, while is not affected by injection pressure and chamber temperature. Additionally, for all conditions shown (and tested), the double-pass system depicts higher average spreading angle than the single-pass setup.

Regarding the optical configurations, the results in the figure follow the same trend as those shown by Pickett et al. [23], of an increased angle value for a schlieren with higher sensitivity (pixel to millimeter ratio in his work). Once again, even though the quantitative difference cannot be all accounted to the optical sensitivity, the sharper contours (e.g. Figure 5.e), that considerably affect angle measurements [23], and the bigger spray observed by the DP setup leads to greater spreading angle values.

\section{Further analysis of the two schlieren configurations}

From the results analyzed in the previous sections, the overall trend found was that the double-pass schlieren system depicts higher spray tip penetration and spreading angle for all conditions tested. Figure 5.e showed a big difference in contrast and contour sharpness between optical configurations, suggesting that the higher sensitivity in the DP caused this difference in the macroscopic description of the spray. But still, other factors need to be accounted for.

Regarding the optical setup and experimental measurements, both diaphragms were set to $4 \mathrm{~mm}$, resulting in an equal sensitivity at the cut-off plane. Background illumination intensity was calibrated to achieve the same levels before starting the experiments campaign. Additionally, reflections, or double-imaging, were filtered in the cut-off plane, due to a similar phenomenon as reported by Pastor et al. [21. Optical accesses typically present small misalignments, caused by differences in the stress of the sealing gaskets, facility assembly, among others, which turn difficult to control. But, curiously, such loss of parallelism becomes an advantage, because these reflections, caused by the optical elements, can be filtered out in the cut-off plane, preventing them from reaching the camera. Regarding the data processing, the same configuration was set for the image processing methodology and moving average technique. Also, with the spray tip penetration definition used (presented in Figure 4 and discussed in section 2.5), the influence of the processing of the data on the final results was diminished.

The differences between setups observed in Figures 5.e and 8 , provide some evidence that, because the light rays are passing twice through the test section, boosting its deflection angle, the DP configuration depicts a bigger spray. Particularly in regions where the difference between the local density of the spray and its surroundings is low, and the deflection angle is small. Figure 13, shows an example of the raw contour obtained before image binarization for each schlieren arrangement, green for SP and orange for DP (corrected with the inclination angle $\psi$ ). A random repetition was chosen with conditions set at $\rho=15.2 \mathrm{~kg} / \mathrm{m}^{3}$, Pinj $=50$ $M P a, \mathrm{~T}=800 \mathrm{~K}$. Three time-steps, after the start of injection, are presented in increasing order from top to bottom. The dashed line, in the spray tip region, represents only an 
Raul Payri, F.J. Salvador, Gabriela Bracho, Alberto Viera; Differences between single and double-pass schlieren imaging on diesel vapor spray characteristics. Applied Thermal Engineering, 2017, 125, 220-231.

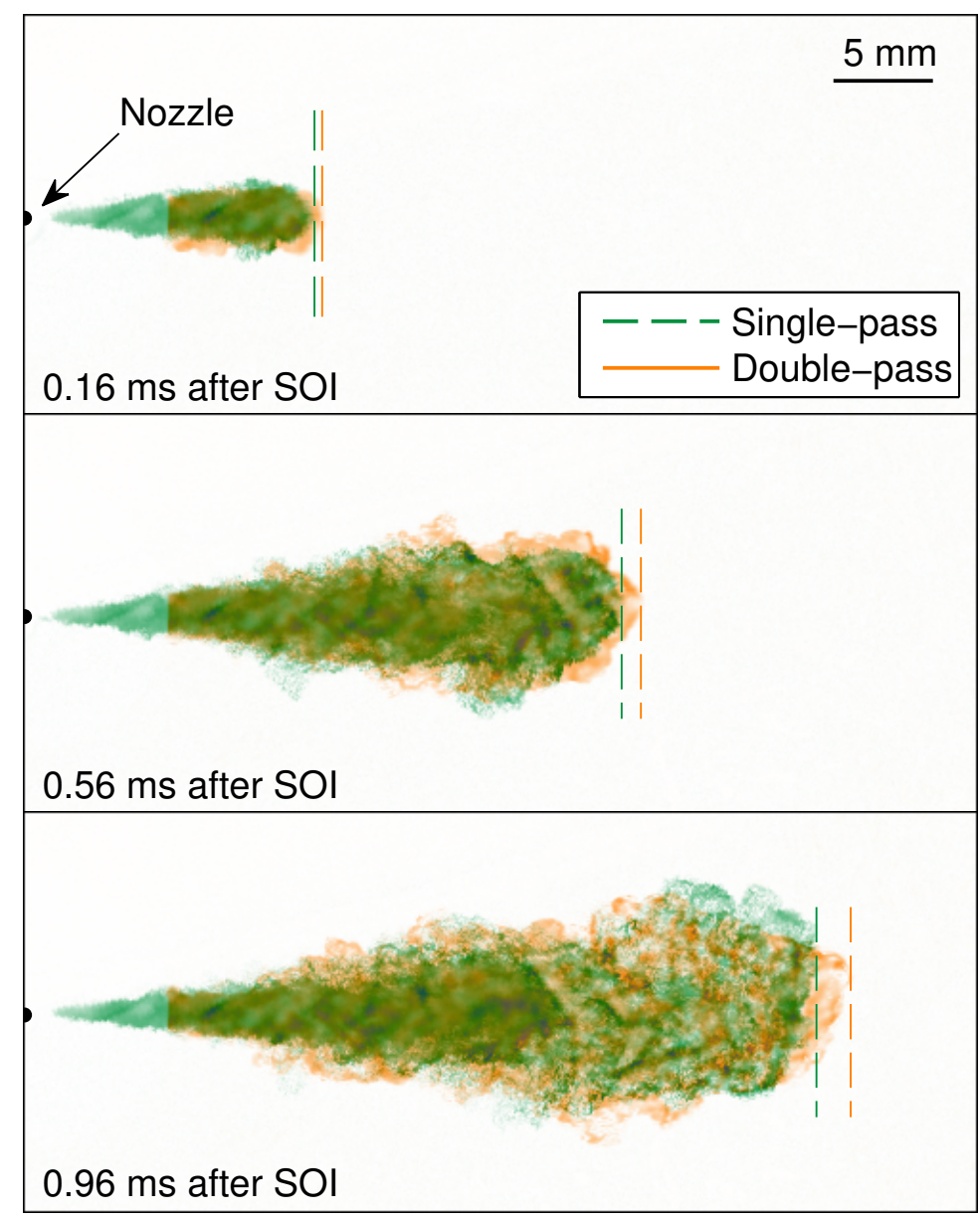

Figure 13: Spray contour before image binarization. The dashed line represents the approximate spray penetration value for each schlieren configuration. $\rho=15.2 \mathrm{~kg} / \mathrm{m}^{3}$, Pinj $=50 \mathrm{MPa}, \mathrm{T}=800 \mathrm{~K}$. For a better color interpretation of this figure, the reader is referred to the web version of this article.

approximation of the penetration because the images are taken before the erode-dilate or pixel connectivity strategies.

From Figure 13, the contour depicted by the single-pass configuration (green) presents smaller tip penetration and spreading angle compared to the one visualized with the doublepass setup (orange), in accordance with the results previously shown. At the early stages of the injection (top image), where the local density of the spray is high compared to the surroundings, both contours show more resemblance. The principle also applies to the latter stages of the injection but in regions located near the nozzle. Note that, although this represents only a random repetition, is still the same injection event. Furthermore, although results presented in section 3 are averaged repetition-wise, and spray tip penetration results are within the range of shot-to-shot deviation, the tendency from Figure 13 was observed throughout all conditions. 
Raul Payri, F.J. Salvador, Gabriela Bracho, Alberto Viera; Differences between single and double-pass schlieren imaging on diesel vapor spray characteristics. Applied Thermal Engineering, 2017, 125, 220-231.

\section{Conclusions}

In this research, vapor phase visualization of a diesel spray was performed with both single and double-pass schlieren imaging setups, to compare their capabilities of determining macroscopic spray variables for the same injection event. Both optical configurations were set up identically regarding camera speed, exposure, pixel to millimeter ratio and diaphragm diameter at the cut-off plane. A three orifice nozzle from the ECN dataset, known as Spray B, was used. Experiments were carried out at a high pressure and temperature vessel, with commercially available diesel, and in a non-reactive environment. A parametric sweep of injection pressure, chamber temperature, and density was performed. The differences between the optical configurations in the background structures and spray development were analyzed for the conditions tested.

The high-temperature mirror used for the double-pass configuration created a stream of flow, cooler than the surroundings, which affected measurements of the single-pass setup near the nozzle (less than 3-4 $\mathrm{mm}$ of penetration). On the contrary, this was not visualized by the DP system, due to the differences in the optical path length (thickness) for each perspective. However, because the double-pass mirror did not fully enclose the nozzle, the first $6 \mathrm{~mm}$ of tip penetration were not captured.

The disturbances of background structures, in the frames before injection, notably increase with increasing chamber density, with less influence for increasing chamber temperature, for the range of conditions tested. The marked impact of density on the background distribution was expected because of its linear scaling with gradients of refractive index. The effect of temperature depends on its distribution along the vessel, as the biggest disturbances appear near the inlet of the hot gases to the test section. The double-pass configuration captures more disruptions (gradients) in the background, compared to the single-pass setup.

For all conditions tested, the spray tip penetration and spreading angle results follow the trend expected from other works in the literature. Penetration increases with increasing injection pressure and decreasing chamber density, and is not affected by temperature. Spreading angle increases with increasing chamber density, with no effect for different injection pressures and temperatures.

Comparing the optical setups, the double-pass system depicts higher spray tip penetration in the latter part of the injection event. Injection pressure and chamber temperature do not play a role in the difference observed. On the contrary, decreasing the density reduces the discrepancy between optical configurations, as they present almost identical values at the lowest density tested. Even though the difference between spray tip penetration results is within the limits of the shot-to-shot dispersion, the deviation reported between both schlieren system is also observed when comparing single injection events. Also, although quantitative measurements of spreading angles depend on multiple factors, the DP configuration also reports higher angle values throughout all conditions.

The double-pass setup produces images with a sharper spray contour and more contrast. Additionally, for the range of data studied, due to its higher sensitivity (as bigger deflection angles), the DP system captures vaporized fuel in regions where the difference between the local density of the spray and its surroundings is low, and thus the deflection angle is small. 
Raul Payri, F.J. Salvador, Gabriela Bracho, Alberto Viera; Differences between single and double-pass schlieren imaging on diesel vapor spray characteristics. Applied Thermal Engineering, 2017, 125, 220-231.

REFERENCES

In general, decreasing the chamber density reduces the influence of the sensitivity because the dissimilarities between densities of these local regions are increased.

\section{Acknowledgments}

This research has been partially funded by FEDER and Spanish Ministerio de Economa y Competitividad through project TRA2015-67679-c2-1-R. Additionally, Alberto Viera is supported through the FPI contract 2016-S2-1361 of "Programa de Apoyo para la Investigacin y Desarrollo (PAID)" of Universitat Poltècnica de València.

The author would like to thank John von Rooy for his collaboration throughout the experiments and processing of the data.

\section{References}

[1] G. S. Settles, Schlieren and Shadowgraph Techniques, Springer Berlin Heidelberg, Berlin, Heidelberg, 2001. doi $10.1007 / 978-3-642-56640-0$.

[2] J. D. Naber, D. L. Siebers, Effects of Gas Density and Vaporization on Penetration and Dispersion of Diesel Sprays, SAE Paper 960034 (1996). doi:10.4271/960034.

[3] R. Payri, J. Gimeno, G. Bracho, D. Vaquerizo, Study of liquid and vapor phase behavior on Diesel sprays for heavy duty engine nozzles, Applied Thermal Engineering 107 (2016) 365-378. doi 10.1016/ j.applthermaleng.2016.06.159.

[4] R. Payri, F. J. Salvador, J. Gimeno, A. Viera, in: H. Tschöke, R. Marohn (Eds.), 10. Tagung Diesel- und Benzindirekteinspritzung 2016, 1, Springer Vieweg, 2017, pp. 133-152. doi $10.1007 /$ 978-3-658-15327-4.

[5] L. M. Pickett, S. Kook, T. C. Williams, Visualization of Diesel Spray Penetration , Cool-Flame , Ignition, High- Temperature Combustion, and Soot Formation Using High-Speed Imaging, SAE Int. J. Engines 2 (2009) 439-459. doi:10.4271/2009-01-0658

[6] J. Benajes, R. Payri, M. Bardi, P. Martí-aldaraví, Experimental characterization of diesel ignition and lift-off length using a single-hole ECN injector, Applied Thermal Engineering 58 (2013) 554-563. doi $10.1016 / j$. applthermaleng.2013.04.044.

[7] R. Payri, J. P. Viera, Y. Pei, S. Som, Experimental and numerical study of lift-off length and ignition delay of a two-component diesel surrogate, Fuel 158 (2015) 957-967. doi:10.1016/j.fuel.2014.11. 072 .

[8] R. Payri, F. J. Salvador, J. Manin, A. Viera, Diesel ignition delay and lift-off length through different methodologies using a multi-hole injector, Applied Energy 162 (2016) 541-550. doi:10.1016/j. apenergy.2015.10.118

[9] R. Payri, J. P. Viera, V. Gopalakrishnan, P. G. Szymkowicz, The effect of nozzle geometry over ignition delay and flame lift-off of reacting direct-injection sprays for three different fuels, Fuel 199 (2017) 76-90. doi:10.1016/j.fuel.2017.02.075.

[10] P. M. Lillo, L. M. Pickett, H. Persson, O. Andersson, S. Kook, Diesel Spray Ignition Detection and Spatial/Temporal Correction, SAE Paper 2012-01-1239 (2012) 1-21. doi:10.4271/2012-01-1239.

[11] J. V. Pastor, R. Payri, J. M. Garcia-Oliver, F. J. Briceño, Schlieren Methodology for the Analysis of Transient Diesel Flame Evolution, SAE International Journal of Engines 6 (2013) 1661-1676. doi:10. 4271/2013-24-0041

[12] J. V. Pastor, R. Payri, J. M. Garcia-Oliver, J.-g. Nerva, Schlieren Measurements of the ECN-Spray A Penetration under Inert and Reacting Conditions, SAE Technical Paper 2012-01-0456 (2012). doi 10 . 4271/2012-01-0456.

[13] A. Montanaro, M. Migliaccio, L. Allocca, V. Fraioli, S.-y. Lee, A. Zhang, J. D. Naber, Schlieren and Mie Scattering Visualization for Single- Hole Diesel Injector under Vaporizing Conditions with Numerical Validation, SAE Technical Paper 2014-01-1406 (2014). doi:10.4271/2014-01-1406. Copyright. 
Raul Payri, F.J. Salvador, Gabriela Bracho, Alberto Viera; Differences between single and double-pass schlieren imaging on diesel vapor spray characteristics. Applied Thermal Engineering, 2017, 125, 220-231.

[14] R. Payri, F. J. Salvador, P. Martí-Aldaraví, D. Vaquerizo, ECN Spray G external spray visualization and spray collapse description through penetration and morphology analysis, Applied Thermal Engineering 112 (2017) 304-316. doi 10.1016/j .applthermaleng. 2016.10.023.

[15] R. Payri, J. M. Garcia-Oliver, T. Xuan, M. Bardi, A study on diesel spray tip penetration and radial expansion under reacting conditions, Applied Thermal Engineering 90 (2015) 619-629. doi 10.1016/ j.applthermaleng.2015.07.042.

[16] L. Allocca, M. Lazzaro, G. Meccariello, A. Montanaro, Schlieren visualization of a GDI spray impacting on a heated wall: Non-vaporizing and vaporizing evolutions, Energy 108 (2016) 93-98. doi: $10.1016 / \mathrm{j}$. energy.2015.09.107.

515 [17] J.-G. Nerva, C. L. Genzale, S. Kook, J. M. Garcia-Oliver, L. M. Pickett, Fundamental Spray and Combustion Measurements of Soy Methyl-Ester Biodiesel, International Journal of Engine Research 14 (2013) 373-390. doi:doi:10.1177/1468087412456688.

[18] B. Knox, C. Genzale, Effects of End-of-Injection Transients on Combustion Recession in Diesel Sprays, SAE International Journal of Engines 9 (2016) 1-18. doi:10.4271/2016-01-0745

[19] S. Kook, L. M. Pickett, Liquid length and vapor penetration of conventional, Fischer Tropsch, coalderived, and surrogate fuel sprays at high-temperature and high-pressure ambient conditions, Fuel 93 (2012) 539-548. doi:10.1016/j.fuel.2011.10.004.

[20] R. Payri, J. Gimeno, J. P. Viera, A. H. Plazas, Needle lift profile influence on the vapor phase penetration for a prototype diesel direct acting piezoelectric injector, Fuel 113 (2013) 257-265. doi:10.1016/j.fuel.2013.05.057.

[21] J. V. Pastor, J. M. Garcia-Oliver, J. M. Pastor, L. D. Zapata, Evaporating Diesel Spray Visualization using a Double-pass Shadowgraphy / Schlieren Imaging, SAE technical Paper 2007-24-0026 (2007). doi: $10.4271 / 2007-24-0026$.

[22] R. Payri, F. J. Salvador, A. Garcia, A. Gil, Combination of visualization techniques for the analysis of evaporating diesel sprays, Energy \& Fuels 26 (2012) 5481-5490. doi:10.1021/ef3008823.

[23] L. M. Pickett, J. Manin, C. L. Genzale, D. L. Siebers, M. P. B. Musculus, C. A. Idicheria, Relationship Between Diesel Fuel Spray Vapor Penetration/Dispersion and Local Fuel Mixture Fraction, SAE International Journal of Engines 4 (2011) 764-799. doi 10.4271/2011-01-0686.

[24] ECN, Engine Combustion Network, Online, 2010. URL: www.sandia.gov/ecn/

[25] R. Payri, J. M. Garcia-Oliver, M. Bardi, J. Manin, Fuel temperature influence on diesel sprays in inert and reacting conditions, Applied Thermal Engineering 35 (2012) 185-195. doi $10.1016 / \mathrm{j}$. applthermaleng.2011.10.027

[26] V. Macian, V. Bermúdez, R. Payri, J. Gimeno, New technique for determination of internal geometry of a Diesel nozzle with the use of silicone methodology, Experimental Techniques 27 (2003) 39-43. doi:10.1111/j.1747-1567.2003.tb00107.x.

[27] J. H. Gladstone, T. P. Dale, Researches on the Refraction, Dispersion, and Sensitiveness of Liquids, Philosophical Transactions of the Royal Society of London 153 (1863) 317-343. doi:10.2307/108799.

[28] M. Bardi, R. Payri, L.-M. Malbec, G. Bruneaux, L. M. Pickett, J. Manin, T. Bazyn, C. L. Genzale, Engine Combustion Network: Comparison of Spray Development, Vaporization, and Combustion in Different Combustion Vessels, Atomization and Sprays 22 (2012) 807-842. doi:10.1615/AtomizSpr. 2013005837.

[29] R. Payri, J. P. Viera, V. Gopalakrishnan, P. G. Szymkowicz, The effect of nozzle geometry over the evaporative spray formation for three different fuels, Fuel 188 (2017) 645-660. doi:10.1016/j.fuel. 2016.06.041.

[30] R. Payri, G. Bracho, P. Marti-Aldaravi, A. Viera, Near field visualization of diesel spray for different nozzle inclination angles in non-vaporizing conditions., Atomization and Sprays 27 (2017) 1-17. doi 10 . 1615/AtomizSpr.2017017949.

[31] D. L. Siebers, Liquid-Phase Fuel Penetration in Diesel Sprays, SAE Technical Paper 980809 (1998) 1-23. doi $10.4271 / 980809$.

[32] Y. Jung, J. Manin, S. A. Skeen, L. M. Pickett, Measurement of Liquid and Vapor Penetration of Diesel Sprays with a Variation in Spreading Angle, SAE Technical Paper 2015-01-0946 (2015). doi 10.4271/ 
2015-01-0946.

[33] R. Payri, J. Gimeno, M. Bardi, A. H. Plazas, Study liquid length penetration results obtained with a direct acting piezo electric injector, Applied Energy 106 (2013) 152-162. doi:10.1016/j.apenergy. 2013.01 .027

[34] J. Manin, M. Bardi, L. M. Pickett, R. Payri, Boundary condition and fuel composition effects on injection processes of diesel sprays at the microscopic level, International Journal of Multiphase Flow 83 (2016) 267-278. doi:10.1016/j.ijmultiphaseflow.2015.12.001.

[35] R. Payri, F. J. Salvador, J. Gimeno, G. Bracho, The effect of temperature and pressure on thermody565 namic properties of diesel and biodiesel fuels, Fuel 90 (2011) 1172-1180. doi:10.1016/j.fuel.2010. 11.015 .

[36] C. Arcoumanis, M. Gavaises, J. M. Nouri, E. Abdul-Wahab, Analysis of the flow in the nozzle of a vertical multi-hole Diesel engine injector, SAE Paper 980811 (1998).

[37] B. Mohan, W. Yang, K. L. Tay, W. Yu, Macroscopic spray characterization under high ambient density conditions, Experimental Thermal and Fluid Science 59 (2014) 109-117. doi:10.1016/j. expthermflusci.2014.08.003.

[38] R. Payri, F. J. Salvador, J. Gimeno, J. P. Viera, Experimental analysis on the influence of nozzle geometry over the dispersion of liquid n-dodecane sprays, Frontiers in Mechanical Engineering 1 (2015) 1-10. doi:10.3389/fmech.2015.00013. 